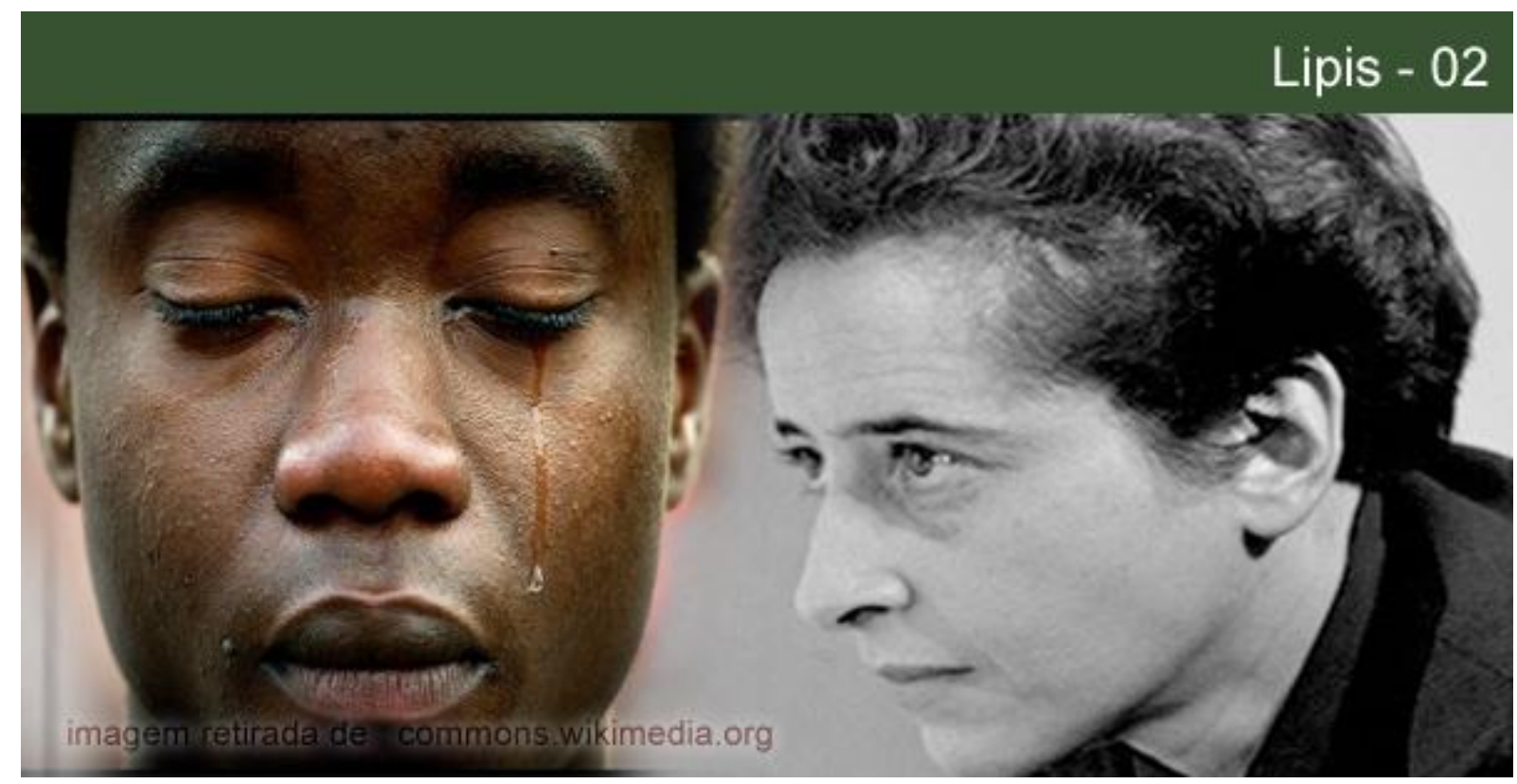

\title{
BANALIDADE DO MAL E MANUTENÇÃO DA ORDEM SOCIAL: O TERCEIRO REICH E O RACISMO NO BRASIL
}

\section{Flora Bezerra dos Santos}

Graduanda em Psicologia. E-mail: florabeer@gmail.com.

\section{Maria Helena Zamora}

Doutora em Psicologia. Professora do Programa de Pós-Graduação em Psicologia Clínica da Pontifícia Universidade Católica (PUC-Rio). Vice-Coordenadora do Laboratório Interdisciplinar de Pesquisa e Intervenção Social da PUC-Rio (LIPIS). E-mail: zamoramh@gmail.com.

Resumo: A partir da sistematização do conceito de banalidade do mal proposto por Hannah Arendt no livro Eichmann em Jerusalém - um relato sobre a banalidade do mal (1963, 1964, 1999), este trabalho busca apontar para as condições de suposta normalidade, em que se instauram mecanismos de desumanização. Os projetos hegemônicos de poder inscrevem, na ordem social, lógicas que corroboram para a anulação de modos de viver encarados como ameaçadores. Consideradas as devidas diferenças, tanto a sistemática nazista quanto a teoria das raças estipulada em fins do século XIX no Brasil, endossaram a existência de hierarquias entre características humanas. Com isso, traça-se um paralelo entre as pautas políticas nos períodos mencionados, a fim de refletir acerca dos efeitos diretos e indiretos que as práticas genocidas manifestam no cotidiano atual.

Palavras-chave: Banalidade do mal. Ordem social. Racismo. Violência. Desumanização.

\section{MAINTENANCE OF SOCIAL ORDER AND BANALITY OF EVIL: THE THIRD REICH AND RACISM IN BRAZIL}

Abstract: Based on the systematization of the concept of banality of evil proposed by Hannah Arendt in the book Eichmann in Jerusalem - a report on the banality of evil (1963, 1964, 1999), this paper aims at indicating the conditions of the supposed normality, in which mechanisms of dehumanization are instaured. The hegemonic projects if power inscribe, in the social order, logics that corroborate with the annulation of ways of living that are seen as threatening. Considering the assumed differences, both the systematic of the nazis and the theory of races stipulated in the end of the 19th century in Brazil, reinforced the existence of hierarchies among human characteristics. Having taken that into account, a parallel is drawn between the political agenda in the

\section{POLÊM!CA $\mid$ LABORE (}

Polêmica - Revista Eletrônica da Uerj - Rua São Francisco Xavier, 524, $1^{\circ}$ andar bloco D, sl.1001 • Tels.: +55 21 2334-4088 / 4087 • http://www.e-publicacoes.uerj.br/index.php/polemica/index http://www.labore.uerj.br • laboreuerj@yahoo.com.br 
aforementioned periods, with the purpose of reflecting upon the direct and indirect effects that the genocidal practices manifest on daily life nowadays.

Keywords: Banality of evil. Social order. Racism. Violence. Dehumanization.

\section{Introdução}

O presente trabalho busca estabelecer um paralelo entre as lógicas que perpassaram projetos de genocídio da Alemanha nazista e a produção de teorias raciais no Brasil, iniciadas no Século XIX, tomando como ponto de partida o conceito de banalidade do mal (ARENDT, [1963/1964] 1999). A obra de Hannah Arendt, Eichmann em Jerusalém - um relato sobre a banalidade do mal ([1963/1964] 1999), analisa o mencionado período alemão através da análise da produção de discursos e verdades que corroboraram para os brutais assassinatos de milhões de pessoas. No Brasil pós-abolição, a teoria das raças, de acordo com Maia e Zamora (2018), Schwarcz (1993), Gahyva, (2013), Vergne (2014) e outros autores, se vincula a processos de subjetivação que ainda nos constituem nos dias de hoje. Tais teorizações têm ligação com estruturas de dominação atuais, que buscam estabelecer postulados para a manutenção de lugares de poder e exploração que corroboram para o genocídio da população negra.

"O trabalho liberta" é a frase que se lia no portão de alguns campos de concentração, como Dachau e Auschwitz I. Como um espaço regido por uma lógica extremamente violenta pode carregar consigo a ideia de libertação? A alienação pelo trabalho pode levar à cega obediência se concedemos à atividade laboral toda a fonte de realização pessoal, reconhecimento e prestígio. O sucesso atribuído às classes dominantes pela via do lugar de destaque social que ocupam é também um fator que renova o próprio sistema de submissão e exploração. Para tal exploração, o nazismo não conheceu limites; trabalhar, naquele lugar, significava caminhar para a morte.

A banalidade do mal, relatada na obra de Arendt ([1963/1964], 1999), atravessa a maneira como Otto Adolf Eichmann entra em contato com a realidade e como atua neste plano. Por mais que soubesse do assassinato de muitas pessoas, o membro do partido alemão só demonstrava competência para assimilar a experiência ao objetivo final de ser respeitado e promovido. No entanto, o oficial em questão não era, exatamente, um ser humano imoral, que abdicou das leis para viver como bem entendeu. Eichmann era um homem de inteligência mediana, inteiramente apto a viver de acordo a lei e a ordem - e assim o fazia.

Não está em questão, no entanto, refletir a moral individualizada de Eichmann, senão para evidenciar que sua maneira de se apresentar é produto de uma sistemática maior, projetada

\section{POLÊM!CA | LABORE}

Polêmica - Revista Eletrônica da Uerj - Rua São Francisco Xavier, 524, $1^{\circ}$ andar bloco D, sl.1001 • Tels.: +55 21 2334-4088/4087 • http://www.e-publicacoes.uerj.br/index.php/polemica/index http://www.labore.uerj.br • laboreuerj@yahoo.com.br 
para a desumanização de determinados grupos. No caso brasileiro, Maia e Zamora (2018) abordam estudiosos como Nina Rodrigues, Arthur de Gobineau e Oliveira Vianna, que elaboraram pesquisas com base no pensamento cientificista, a fim de legitimar a existência de uma hierarquia racial que estipula a humanidade do negro como inferior à branca. As teorias raciais produziram efeitos na atualidade, refletidas na desigualdade política vivenciada no cotidiano de negros em relação a brancos. Para concluir, o psicólogo Celso Vergne (2014), em A trama da besta: a construção cotidiana do genocídio negro no Rio de Janeiro, demonstra como as práticas de genocídio não pertencem ao passado e são reforçadas não só pelo Estado, mas por uma parcela da população privilegiada que não se concebe enquanto componente de uma lógica de opressão produzida para eliminar corpos concebidos como indesejáveis.

\section{Eichmann e a atuação no projeto antissemita da Alemanha nazista}

A presença de Adolf Eichmann em Jerusalém teve conteúdo simbólico para muito além de sua acusação individual. "Não é um indivíduo que está no banco dos réus neste processo histórico, não é apenas o regime nazista, mas o antissemitismo ao longo de toda a história." (ARENDT, [1963/1964] 1999, p. 30). De acordo com a Corte da Casa de Justiça Israelense, o processo se baseia no sofrimento e devastação experienciados pelos judeus e não especificamente no que Eichmann fez. Sob essa perspectiva, apenas um tribunal judeu poderia fazer justiça aos judeus.

O réu, ao contrário do que poder-se-ia esperar, não aparentava um homem de conduta "perversa" ou "estereotipada", ao olhar dos presentes. Tratava-se de um sujeito sem demonstrações de falta de sanidade moral ou legal. Este declara que "o que ele fizera era crime só retrospectivamente, e ele sempre fora um cidadão respeitador das leis, porque a ordem de Hitler, que sem dúvida executou o melhor que pôde, possuíam "força de lei" no Terceiro Reich" (ARENDT, [1963/1964] 1999, p. 35). Eichmann se curvar à lei, como grande parte de trabalhadores alemães, que tinham entre suas maiores preocupações a servidão à ordem e a seus superiores, na intenção de ascender socialmente.

A acusação tinha a premissa de que o acusado, como "toda pessoa normal" devia ter consciência da natureza de seus atos, e Eichmann era efetivamente normal na medida em que "não era exceção dentro do regime nazista". No entanto, nas condições do Terceiro Reich, só se podia esperar que apenas as "exceções" agissem "normalmente". (ARENDT, [1963/1964] 1999, p. 38).

\section{POLÊM!CA $\mid$ LABORẸ}

Polêmica - Revista Eletrônica da Uerj - Rua São Francisco Xavier, 524, $1^{\circ}$ andar bloco D, sl.1001 • Tels.: +55 21 2334-4088/4087 • http://www.e-publicacoes.uerj.br/index.php/polemica/index http://www.labore.uerj.br • laboreuerj@yahoo.com.br 
O lema "A batalha pelo destino do povo alemão", adotado pelo partido nazista, foi apontado por Arendt em três aspectos: "sugeria, em primeiro lugar que a guerra não era guerra"; “em segundo, que fora iniciada pelo destino e não pela Alemanha”; "e, em terceiro, que era questão de vida ou morte para os alemães, que tinham que aniquilar seus inimigos ou serem aniquilados." (ARENDT, op. cit., p. 65).

No começo, o funcionamento político do Terceiro Reich estava direcionado a tornar o território judenrein, isto é, livre dos judeus. Foram lançadas propagandas que depreciavam sua imagem e os comparavam a insetos e a outros símbolos de valor pejorativo. Com efeito, os judeus foram privados de participação política, ocupação em cargos públicos, aparição midiática e os que tivessem obtido cidadania alemã posteriormente a 2 de agosto de 1914 (início da Primeira Guerra Mundial) estavam sujeitos à expulsão, pois a ordem era a sua desnaturalização. Tendo recebido leis próprias, os judeus viviam uma "cidadania incompleta" e a obrigação a uma existência discreta para, talvez, não sofrerem mais exclusões.

Eichmann se torna, para bem exercer de suas funções burocráticas, um "perito na questão judaica", trabalhando diretamente com as providências para a evasão deles do território alemão. A partir de um processo de racialização, desumanização e perseguição, judeus começam a ser evacuados, deportados ou não, supostamente, a fim de encontrar condições favoráveis à vida.

No entanto, para o secretário nazista, há um desprendimento da realidade enquanto tal, como se a evasão judaica fosse uma escolha espontânea ou uma fuga esvaziada de significação.

Os judeus "desejavam" imigrar, e e ele, Eichmann, estava ali para ajudá-los, porque
aconteceu de, ao mesmo tempo, as autoridades nazistas terem expressado o desejo
de ver o Reich judenrein. Os dois desejos coincidiam, e ele, Eichmann, podia fazer
"justiça a ambas as partes". No julgamento, ele jamais cedeu um milímetro quando
chegava nessa parte da história, embora concordasse que hoje, quando "os tempos
mudaram tanto", os judeus podem não gostar mais de se lembrar desse "esforço
conjunto" e ele não queria "ferir seus sentimentos [...]". (ARENDT, [1963/1964]
1999, p. 60).

Segundo Arendt (1963, 1964, 1999, p. 62), foi-se compreendendo, perante às declarações de Eichmann no julgamento, que a dificuldade de comunicação com o réu não se constituía por conta de mentiras. Ele fazia uso de uma linguagem pontuada por expressões e clichês de sua época, que serviam como defensiva contra os apontamentos dos outros presentes. Sua elaboração de discurso ia demonstrando aos ouvintes que ele não acessava - não refletia a perspectiva de outra pessoa.

\section{POLÊM!CA $\mid$ LABORE}

Polêmica - Revista Eletrônica da Uerj - Rua São Francisco Xavier, 524, $1^{\circ}$ andar bloco D, sl.1001 • Tels.: +55 21 2334-4088/4087 • http://www.e-publicacoes.uerj.br/index.php/polemica/index http://www.labore.uerj.br • laboreuerj@yahoo.com.br 
Sem dúvida, os juízes tinham razão quando disseram ao acusado que tudo o que dissera era "conversa vazia" - só que eles pensaram que o vazio era fingido, e que o acusado queria encobrir outros pensamentos que, embora hediondos, não seriam vazios. Essa ideia parece ter sido refutada pela incrível coerência com que Eichmann, apesar de sua má memória, repetia palavra por palavra as mesmas frases feitas e clichês semi-inventados [...] toda vez que se referia a um incidente ou acontecimento que achava importante. (ARENDT, [1963/1964] 1999, p. 62).

Seguindo o projeto de "livrar" a Alemanha da presença judaica, traça-se uma primeira solução, que consiste na expulsão e que se expressa a partir das políticas de restrição de cidadania e deportação mencionadas. "Foi só com a eclosão da guerra, em $1^{\circ}$ de setembro de 1939, que o regime nazista tornou-se abertamente totalitário e abertamente criminoso." (op. cit., p. 82). Emerge no projeto do partido, uma segunda solução para lidar com o suposto problema: a concentração. A mentalidade objetiva, característica da Schutzstaffel - também conhecida por SS, organizada como um grupo paramilitar vinculado ao partido nazista -, abordava os campos de concentração como medida administrativa e campos de extermínio como medida econômica, naturalizando a ideia de uma brutal e total privação de liberdade e da própria vida. "Uma vez que não havia território para onde pudessem ser "evacuados", a única "solução" era o extermínio (op. cit., p. 83).”. Nesse período, a deportação e a saída não configuravam mais os últimos estágios da medida, tornando o departamento de Eichmann meramente instrumental.

\section{A ordem no Terceiro Reich}

“O Führer ordenou que os judeus sejam eliminados fisicamente.” (op. cit., p. 98). A chamada "Solução Final" decretava o assassinato de todos aqueles que estavam presos em campos de concentração. No entanto, a palavra assassinato foi substituída por tratamento especial. Tratar tecnicamente questões que envolvem a morte de populações foi uma estratégia no governo de Hitler para que os indivíduos não entrassem em contato e se compadecessem com o projeto genocida em vigor. "O efeito direto desse sistema de linguagem não era deixar as pessoas ignorantes daquilo que estavam fazendo, mas impedi-las de equacionar isso com seu antigo e "normal" conhecimento do que era assassinato e mentira (op. cit., p. 101)". Nesse sistema, solução final nada mais indica que extermínio; a palavra eliminação foi substituída por evacuação. A eliminação por gás foi encarada como uma forma de eutanásia, uma morte misericordiosa dada às pessoas como um assunto médico, similar ao controle de pragas, de insetos.

\section{POLÊM!CA $\mid$ LABORE}

Polêmica - Revista Eletrônica da Uerj - Rua São Francisco Xavier, 524, $1^{\circ}$ andar bloco D, sl.1001 • Tels.: +55 21 2334-4088/4087 • http://www.e-publicacoes.uerj.br/index.php/polemica/index http://www.labore.uerj.br • laboreuerj@yahoo.com.br 
Foi organizada uma reunião, na qual Eichmann foi convocado e onde ocupava o posto mais baixo na hierarquia dos homens presentes. A Conferência de Wansee, em janeiro de 1942 (ARENDT, [1963/1964] 1999, p. 128), voltou-se para questões legais da Solução Final, como o que fazer com as pessoas que não eram puramente judias ou como lidar com o "problema" a partir de uma solução total da questão judaica na Europa. Eichmann, enquanto um homem de exercícios burocráticos, estava ali disponível para seus superiores, expressando uma anulação de qualquer sentimento de culpa após este dia. Quem era ele para ter suas próprias ideias sobre o assunto, se seus superiores o endossavam? Quem haveria de ser o juiz? (ARENDT, [1963/1964] 1999, p. 130)

Eichmann não era um mercenário, que só pensava em habitar uma terra sem leis morais. O que verdadeiramente acreditava era no sucesso, padrão partilhado entre os que habitam a "boa sociedade". Ademais, quando interrogado no tribunal sobre a reunião, sua memória é uma recordação pessoal do momento em que teve a oportunidade de beber e fumar com seus chefes. "Naquele momento, eu me senti uma espécie de Pôncio Pilatos, pois me livrei de toda a culpa (ARENDT, [1963/1964] 1999, p. 130)". Ao longo de todo o julgamento, as lembranças de Eichmann, quando não escassas, dizem respeito a todo um sistema burocrático onde um homem medíocre trabalha para conseguir realização social. Apresentava "total ignorância de tudo que não fosse direta, técnica e burocraticamente ligado a seu trabalho, sem falar de sua memória extremamente deficiente." Eichmann era um cidadão respeitador das leis. Cumpria leis e ordens, alcançando um nível de "obediência cega". "Aja de tal modo que o Führer, se souber de sua atitude, a aprove.” (FRANK, 1942, p. 15-6 apud ARENDT, 1999, p. 153).

\begin{abstract}
'Hitler,' disse ele, 'pode ter estado errado do começo ao fim, mas uma coisa está acima de qualquer dúvida: esse homem conseguiu abrir seu caminho de cabo lanceiro do exército alemão até fuhrer de um povo de quase 80 milhões [...]. Bastava o seu sucesso para me provar que eu devia me subordinar a esse homem.' Sua consciência ficou efetivamente tranquila quando ele viu o zelo e o empenho com que a "boa sociedade" de todas as partes reagia ao que ele fazia. Ele não precisava cerrar os ouvidos para a voz da consciência, como diz o preceito, não porque ele não tivesse nenhuma consciência, mas porque sua consciência falava com "voz respeitável", com a voz da sociedade respeitável a sua volta (ARENDT, [1963/1964] 1999, p. 142).
\end{abstract}

Banalidade do mal é o conceito que perpassa todos esses pontos históricos, mas que não se aplica unicamente ao contexto da Segunda Guerra Mundial. O que Hannah Arendt relata é o fato de um homem que esteve diretamente envolvido com o genocídio de milhões de pessoas e que quando levado a julgamento se mostra um sujeito ordinário, fruto das ambições da ordem

\title{
POLÊM!CA $\mid$ LABORE
}

Polêmica - Revista Eletrônica da Uerj - Rua São Francisco Xavier, 524, $1^{\circ}$ andar bloco D, sl.1001 • Tels.: +55 21 2334-4088/4087 • http://www.e-publicacoes.uerj.br/index.php/polemica/index http://www.labore.uerj.br • laboreuerj@yahoo.com.br 
social. Seria um indicativo para o potencial totalitário que a sistemática capitalista produz subjetivamente?

Não se trata de resgatar dados que humanizem Eichmann e busquem justificar suas condutas ou relativizar o caráter assassino de suas ações. A questão é, portanto, a tirania que a manutenção da lei pode alcançar e a turva obediência que a ordem social inscreve àqueles que dela podem favorecer-se. "A estonteante disposição de Eichmann, primeiro na Argentina, depois também em Jerusalém a admitir seus crimes devia-se menos a sua capacidade criminosa de autoengano do que à aura de sistemática hipocrisia que constituía a atmosfera geral, aceita por todos no Terceiro Reich" (ARENDT, [1963/1964] 1999, p. 65).

\section{O Brasil e as teorias das raças}

Ao final do século XIX e início do século XX, autores como Arthur de Gobineau, Nina Rodrigues e Oliveira Vianna se dedicaram à produção de discursos cientificistas para delinear as lógicas das relações raciais no Brasil.

\footnotetext{
Trata-se de investigar como eles contribuíram para a produção de verdades que, de forma direta ou indireta, definiram hierarquias sociais, códigos legais, políticas públicas, estabelecimentos de ensino, instituições como prisões, manicômios e hospitais, endereçadas a um grupo específico da sociedade. Dão-se então, em uma tessitura de poder e verdade, formas subjetivas que vigoraram em um determinado período histórico, mas cujos efeitos ainda são sentidos. (MAIA, ZAMORA, 2018).
}

A história da colonização do Brasil é constituída pelas relações de exploração que a metrópole portuguesa institui a partir do momento em que ocupa a terra e entra em contato com os povos originários. Com o regime escravocrata, milhões de pessoas são brutalmente trazidas do continente africano para trabalharem em engenhos e lavouras. A abolição formal deste sistema ocorre somente após três séculos e ainda sem investimentos em políticas públicas que se preocupassem com a inserção política, social e econômica dos trabalhadores libertos. "Entre a abolição da escravatura (1888) e a institucionalização da CLT (Consolidação das Leis do Trabalho) por Vargas em 1943, ocorre um processo complexo, em que ideias importadas da Europa, de cunho cientificista, iniciam uma vasta produção de subjetividade racista que podemos reconhecer na atualidade.” (MAIA, ZAMORA, 2018).

Arthur de Gobineau (1853-1855) declarou a superioridade de povos escandinavos a partir de uma suposta condição de pureza. Sendo assim, teriam a incumbência de

\section{POLÊM!CA $\mid$ LABORE}

Polêmica - Revista Eletrônica da Uerj - Rua São Francisco Xavier, 524, $1^{\circ}$ andar bloco D, sl.1001 • Tels.: +55 21 2334-4088 / 4087 • http://www.e-publicacoes.uerj.br/index.php/polemica/index http://www.labore.uerj.br・ laboreuerj@yahoo.com.br 
responsabilizar-se pela não degenerescência, isto é, pela não miscigenação, a fim de não “degenerar” a raça ariana, mantendo uma suposta condição de pureza.

\begin{abstract}
Gobineau, em sua tentativa de instituir uma hierarquia racial, parte do princípio de que a sociedade começa a se formar a partir da expansão dos povos germânicos nas camadas étnicas dos outros grandes grupos que povoaram o Velho Mundo, a saber: egípcios, assírios, chineses, gregos, romanos, germânicos e, na América, as três grandes civilizações pré-colombianas. Este pensamento carrega um paradoxo: a obrigatoriedade da expansão ariana ocorrer por meio da miscigenação, que ele tanto advertia ser perigosa. A mesma força civilizatória que a miscigenação produz traz a degeneração intrínseca a si própria. Contudo, havia menos danos caso a raça ariana fosse dominante (...) Junto com a burguesia, o franco desenvolvimento do capitalismo, a decadência do soberano e o surgimento da sociedade disciplinar, a guerra das raças passa a ser a guerra da raça. O inimigo externo passa a ser interno, o controle dos corpos passa a ser do Estado e a racialização científica estabelece a soberania da raça branca em relação às não brancas. (MAIA, ZAMORA, 2018).
\end{abstract}

Nina Rodrigues (1862-1906) se dedica a estudar os africanos no Brasil e sua relação com a criminalidade. Segundo Maia e Zamora (2018), Rodrigues - atuante em diversas áreas, entre elas a medicina e a jurídica - trata a escravidão como uma condição necessária para o desenvolvimento social dos negros, naturalizando o regime escravocrata e fixando a ideia de que o negro está sempre em defasagem em relação ao branco.

O autor nos fala claramente do saber psychologico, o que, de alguma forma, anuncia o discurso que posteriormente instituiria a prática do psicólogo nas engrenagens penais e judiciárias. Em grande medida, a demanda por tal especialista surge das lógicas raciais, da necessidade de previsão do comportamento antissocial dos mestiços e de proteger a sociedade da inevitável degradação hereditária que os acomete. (MAIA, ZAMORA, 2018).

Oliveira Vianna, adepto da política eugenista, traça um panorama que considera adequado para o Brasil se constituir enquanto nação. A Eugenia visa o alcance de um povo tipicamente brasileiro, a partir da miscigenação entre raças superiores e inferiores, resultando em um aprimoramento destas. Em outras palavras, a Eugenia é um projeto que envolve políticas públicas para a diminuição da população negra no Brasil.

A arianização progressiva era uma proposta de política pública que visava à redução da população negra pela miscigenação com a raça branca superior. A arianização era uma saída civilizatória para o Brasil. Na seleção natural, o negro se extinguiria pela seleção social, que diz respeito à raça branca ser mais forte e mais bela, e por isso dominadora socialmente; a razão patológica, que se caracteriza pelas condições precárias de vida, que trariam maior contato com doenças; e finalmente a econômica, que, pela precariedade em que os negros viviam, levaria à menor expectativa de vida. (MAIA, ZAMORA, 2018).

\title{
POLÊM!CA $\mid$ LABORE
}

Polêmica - Revista Eletrônica da Uerj - Rua São Francisco Xavier, 524, $1^{\circ}$ andar bloco D, sl.1001 • Tels.: +55 21 2334-4088/4087 • http://www.e-publicacoes.uerj.br/index.php/polemica/index http://www.labore.uerj.br • laboreuerj@yahoo.com.br 
As políticas de embranquecimento, o racismo cientificista, bem como a insistente negação das vidas negras corroboram para demarcar o lugar de um outro, menos humano. “A descaracterização da humanidade do outro passa não só pela cor da pele, mas pelo julgamento de hábitos, práticas cotidianas, modos de sentir e comunicar. Se o transformo em algo mais próximo do animal, é possível exterminar, pois não se trata de outro como eu.” (VERGNE et al., 2015).

\section{Manutenções da lógica racial nos dias de hoje}

Segundo o Atlas da Violência produzido pelo Instituto de Pesquisa Econômica Aplicado (IPEA) e o Fórum Brasileiro de Segurança Pública (FBSP), “de cada 100 pessoas que sofrem homicídio no Brasil, 71 são negras" (2017, p. 30). Territorialidades marcam os corpos que circulam pelo tecido urbano a partir de exercícios de violência direcionados à população pobre e negra. Os projetos históricos de delineamento racial operam, até hoje, a partir da produção de um perfil suspeito, criminalizável, logo, matável. Vergne (2014) aponta que a concepção de um outro pelas instâncias do poder, tido como inimigo, é elemento constituinte em nossa maneira de viver em sociedade.

Os ideais de ordenar e controlar, característicos da modernidade (BAUMAN, 1999 apud VERGNE, 2014, p. 19), impulsionam para uma gestão de Estado pautada na violenta dominação e exploração entre classes sociais. A distinção do inimigo é arbitrária e, portanto, pode perpassar por qualquer determinação das classes dominantes. Traçando um paralelo com os judeus que vivenciaram as atrocidades do Terceiro Reich, há no Brasil um desejo das elites brancas de eliminação da população negra.

A violência racista do branco é exercida, antes de tudo, pela impiedosa tendência a destruir a identidade do sujeito negro. Este, através da internalização forçada dos valores e ideais do branco, é obrigado a adotar para si modelos incompatíveis com seu próprio corpo - o fetiche do branco, da brancura. (VERGNE et al., 2015).

Lugares hegemônicos são ocupados e manejados pela branquitude, e a presença negra é ainda debatida superficialmente no campo da subjetividade, no Brasil. O olhar do branco é voltado para demarcar o exótico, não-eu, o incompreensível, tão pejorativamente a ponto de comparar humanos a insetos e demônios. A construção de uma nação brasileira é controversa e ainda está em curso, no entanto, pode-se identificar o desejo de sermos uma nação distinta, sem a presença de efeitos negros de subjetivação (VERGNE, 2014, p. 35-38).

\section{POLÊM!CA $\mid$ LABORE}

Polêmica - Revista Eletrônica da Uerj - Rua São Francisco Xavier, 524, $1^{\circ}$ andar bloco D, sl.1001 • Tels.: +55 21 2334-4088 / 4087 • http://www.e-publicacoes.uerj.br/index.php/polemica/index http://www.labore.uerj.br • laboreuerj@yahoo.com.br 
Pensar o genocídio através de sua construção na subjetividade impõe uma reflexão necessária: violências, crimes e mortes, não devem ser tomados como naturais menos ainda, mortes violentas que acontecem por efeitos de ódios e rejeições. Agressividade, uma característica humana, comum a outros seres vivos, não é o mesmo que homicídio por ódio ao diferente. (VERGNE, 2014, p. 34).

A utilização da palavra genocídio é, segundo Vergne (2014, p. 34) “como sendo o efeito de um conjunto de práticas cotidianas baseado no desejo de eliminação, ou de afastamento do outro, consentindo, mesmo que silenciosamente, em sua eliminação". Sendo assim, a expressão de tal desejo extrapola homicídios físicos, caracterizando também formas menores de matar.

Se o genocídio também é caracterizado por expressões mais sutis, é necessário, então, que olhemos para nossas práticas, a fim de detectar as formas de opressão que reproduzimos cotidianamente. É um trabalho incômodo, afinal, pensar-se como agente produtor da morte pode ser absolutamente indesejado. Contudo, o silenciamento só perpetua a gravidade dos atos propagados contra a maioria da população (VERGNE, 2014, p. 39).

O mal tende a se mostrar de forma cada vez mais intensa, não como algo que não deva ser percebido. O que chamaríamos de "mal" cada vez mais tem se mostrado como uma necessidade lógica, neutra, inevitável. A racionalidade do capital moderno tende a apagar a apagar traços de vínculos calorosos entre pessoas. O consumo tende a ser cada vez mais o mote da relação humana. E o mal, se torna uma questão íntima e pessoal, excessivamente singular, quase incomunicável. (VERGNE, 2014, p. 36).

As práticas genocidas são, corriqueiramente, associadas ao passado, como eventos já superados no contexto atual e, ademais, a mentes doentias. No entanto, é importante frisar que nunca, anteriormente, na história humana, os números de mortes foram tão altos como na modernidade, nem alcançaram tamanha sofisticação sistemática (VERGNE, 2014, p. 34).

É possível pensar no conceito de banalidade do mal aplicado à realidade dominadora da branquitude no Brasil atual? Existem fartas demonstrações da anulação de modos de existência e, em nosso país, são os corpos de indígenas e negros os maiores alvos. O mal é experienciado como algo exterior a nós e presente em certas pessoas, sem que se perceba o quanto esta desumanização é replicável, por exemplo, nas expressões e práticas racistas.

O mal parece inevitável nas relações atuais, uma vez que nos fazemos cada vez menos afetáveis ao outro e menos conscientes e sensíveis à sua realidade diversa. O apagamento de vínculos calorosos entre as pessoas, o mal se mostra algo a ser intensificado, uma necessidade lógica. Cabe a nós a análise da construção de tais posições subjetivas, tensionando-as para um maior grau de reflexão e, enfim, para a mudança.

\section{POLÊM!CA $\mid$ LABORE}

Polêmica - Revista Eletrônica da Uerj - Rua São Francisco Xavier, 524, $1^{\circ}$ andar bloco D, sl.1001 • Tels.: +55 21 2334-4088 / 4087 • http://www.e-publicacoes.uerj.br/index.php/polemica/index http://www.labore.uerj.br • laboreuerj@yahoo.com.br 


\section{Referências}

ARENDT, H. Eichmann em Jerusalém: um relato sobre a banalidade do mal. São Paulo: Companhia das Letras, 1999.

BUENO, S.; CERQUEIRA, D.; HANASHIRO, O.; LIMA, A.; LIMA, R. S.; MACHADO, P. H.; VALENCIA, L. I. Atlas da Violência 2017. Brasília: Ipea, 2017. Disponível em:

<http://www.ipea.gov.br/atlasviolencia/download/2/atlas-2017>. Acesso em: 30 dez. 2018.

GAHYVA, H. O bom filho a casa torna: Gobineau refugiado na hierarquia familiar. Tempo Social, revista de sociologia USP [online], v. 25, n. 1, p. 235-256, 2013.

MAIA, K. S.; ZAMORA, M. H. N. O Brasil e a lógica racial: do branqueamento à produção de subjetividade do racismo. Psicol. clín., Rio de Janeiro, v. 30, n. 2, p. 265-286, 2018. Disponível em:

$<$ http://pepsic.bvsalud.org/scielo.php?script=sci_arttext\&pid=S0103-56652018000200005\&lng=pt\&nrm=iso>. Acesso em: 19 set. 2018 .

SCHWARCZ, L. M. O espetáculo das raças: cientistas, instituições e questão racial no Brasil, 1870-1930. São Paulo: Companhia das Letras, 1993. Disponível em:

<http://search.ebscohost.com/login.aspx?direct=true \&db=cat06910a\&AN=puc. $95174 \&$ lang=pt-br\&site=edslive $\&$ scope $=$ site $>$. Acesso em: 17 set. 2018.

VERGNE, C. M. A trama da besta: a construção cotidiana do genocídio do negro no Rio de Janeiro. 2014. 124 f. Tese (Doutorado em Psicologia Clínica) - Departamento de Psicologia, Pontifícia Universidade Católica do Rio de Janeiro, Rio de Janeiro, 2014.

VERGNE, C. M.; VILHENA, J.; ZAMORA, M. H.; ROSA, C. M. A palavra é ... genocídio: a continuidade de práticas racistas. Revista Psicologia \& Sociedade, v. 27, n. 3, p. 516-528, 2015. Disponível em: <http://www.scielo.br/pdf/psoc/v27n3/1807-0310-psoc-27-03-00516.pdf.>. Acesso em: 20 set. 2018.

Recebido em: 01/12/2018.

Aceito em: 30/12/2018.

\section{POLÊM!CA $\mid$ LABORE}

Polêmica - Revista Eletrônica da Uerj - Rua São Francisco Xavier, 524, $1^{\circ}$ andar bloco D, sl.1001 • Tels.: +55 21 2334-4088 / 4087 • http://www.e-publicacoes.uerj.br/index.php/polemica/index http://www.labore.uerj.br • laboreuerj@yahoo.com.br 